\title{
Overview of Short-Circuit Contribution of Various Distributed Generators on the Distribution Network
}

\author{
Panagiotis Karaliolios \\ Technische Universiteit Eindhoven \\ p.karaliolios@tue.nl
}

\author{
Anton Ishchenko \\ Technische Universiteit Eindhoven \\ a.ishchenko@tue.nl
}

\author{
Edward Coster \\ Technische Universiteit Eindhoven \\ Stedin \\ ecoster@tue.nl
}

\author{
Johanna Myrzik \\ Technische Universiteit Eindhoven \\ j.m.a.myrzik@tue.nl
}

\author{
Wil Kling \\ Technische Universiteit Eindhoven \\ w.1.kling@tue.nl
}

\begin{abstract}
Apart from the positive technical consequences like reducing losses, the increasing penetration of Distributed Generation (DG) units connected to the distribution network, has lead to the increase of the short-circuit (sc) currents and the fault level. Therefore it is important to know the contribution of each unit. This paper presents the available analytical equations to calculate the short-circuit current, and makes a comparison between the IEC 60909 and the results obtained by the simulations in a test network that incorporates these units.
\end{abstract}

Keywords: Decentralized Generation, short circuit, IEC 60909, Doubly Fed Induction Generator

\section{INTRODUCTION}

The continuous increase in energy consumption as well as the demand for clean energy has lead to a turn on the way electricity is produced. Nowadays generators are connected on the distribution network and their share in the production is expected to be significantly increased in the near future. Among the problems that have arisen, sc level contribution is of great importance as it is a factor that will also determine the penetration level that can be achieved with the current installed equipment. Therefore, it is essential to know how these units contribute to the sc current.

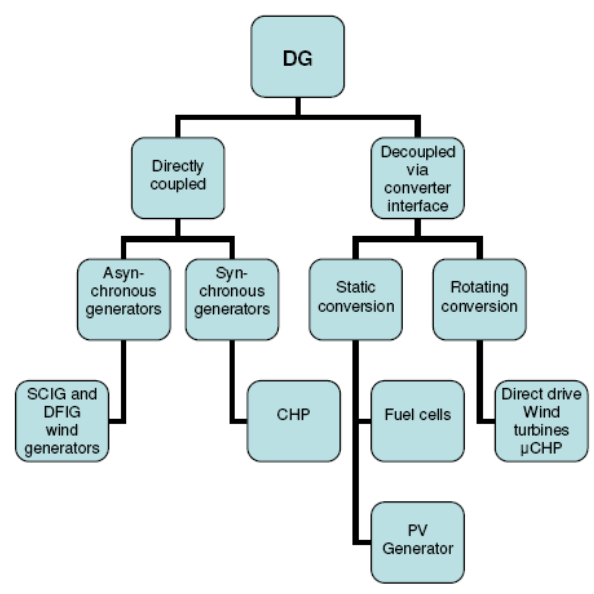

Fig. 1. Classification of DG units
The contribution is mainly determined by the way the generator is connected to the network. Based on this, two main categories can be distinguished as it is shown in Fig. 1.

The sc contribution of Converter Interfaced Distributed Generators, is low and mainly determined by the thermal limit of the semiconductors, therefore it is usually limited up to $2 \mathrm{p} . \mathrm{u}$. of the nominal current [1-3].

In this paper, the directly coupled generators will be treated, as their contribution is much more critical. In the first part, an overview of the available methods to calculate the sc current will be presented. Special attention is given to the Doubly Fed Induction Generator (DFIG), where a way how to treat the current IEC standards is proposed, since these new generators, are not treated. Finally, the accuracy of the IEC method in contrast with Electromagnetic Transient (EMT) simulations is discussed for a test network carried in DigSilent Power Factory software, as well as the effect that sc behavior of the examined DG can have in the increase of the penetration level.

\section{SC CONTRIBUTION}

\section{General}

Fault level and fault current calculations are indispensable tools during the grid design phase. The purpose of sc calculations is to determine:

1. Thermal effect of fault currents on grid components

2. Mechanical stresses on grid components

3. Coordination of protection devices

To assess the mentioned effects in [4] a couple of fault current quantities are defined. The most important quantity is the initial symmetrical sc current $\mathrm{I}_{\mathrm{k}}{ }^{\prime}$.

Other quantities are:

- $\quad$ Peak sc current, $\mathrm{I}_{\mathrm{p}}$

- Steady state sc current $I_{k}$

- Breaking current $\mathrm{I}_{\mathrm{b}}$

All defined quantities are based on the initial symmetrical sc current.

During a sc transients will occur. This can be explained with a simple equivalent of a feeder which is shown in Fig. 2. 


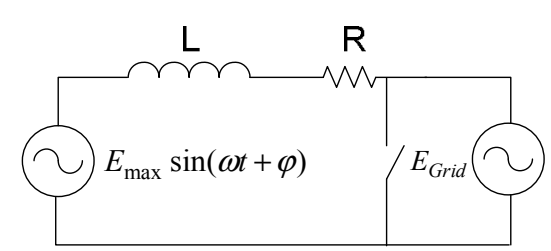

Fig. 2. Network equivalent

This network after fault occurrence at $\mathrm{t}=0$ can be described with the following differential equation:

$$
L \frac{d i}{d t}+R \cdot i=E_{\max } \sin (\omega t+\phi)
$$

The solution of the differential equation is:

$$
\begin{aligned}
& i=e^{-\frac{R}{L} t}\left(\frac{-E_{\max }}{\sqrt{R^{2}+\omega^{2} L^{2}}} \sin \left(\phi-\tan ^{-1}\left(\frac{\omega L}{R}\right)\right)\right) \\
& +\frac{E_{\max }}{\sqrt{R^{2}+\omega^{2} L^{2}}} \sin \left(\omega t+\phi-\tan ^{-1}\left(\frac{\omega L}{R}\right)\right)
\end{aligned}
$$

The first term of the expression represents the decaying DC-component and the second term is the stationary current. The DC-component is dependent on the moment the fault occurs with respect to the voltage. The DC component appears when the value of the voltage is not 0 at the moment of the sc. In a case of a $3 \mathrm{ph} \mathrm{sc}$, there will always be a DC component, in at least two phases. The damping of the DCcomponent is determined by the $\mathrm{R} / \mathrm{L}$ ratio.

It is obvious that when the network becomes complicated, the solution of differential equations, which require the knowledge of the initial conditions at the moment the sc occurs, would become problematic. Therefore simplifications have to be made as in IEC.

In IEC standards, the calculation of the various quantities is performed in several steps. First, the subtransient sc current $\mathrm{I}_{\mathrm{k}}$ " is calculated and by using some factors all the needed quantities can be found:

$$
I_{k}^{\prime \prime}=c U_{n} /(\sqrt{3} Z)
$$

where $U_{n}$ is the nominal voltage of the network (rms phasephase value) and $\mathrm{Z}$ the equivalent sc impedance. The $\mathrm{c}$ factor is introduced to take into account variations of the actual voltage with respect to nominal value (in pre-fault situation). The transients of the generators, as well as the omitted loads, and its values can be found in [5]. The equivalent impedance takes into consideration resistances when the $\mathrm{R} / \mathrm{X}$ ratio at the point of the sc is more than 0.35 .

Then the peak current is derived from:

$$
I_{p}=k \sqrt{2} I_{k}^{\prime \prime}
$$

In order to include the DC component and the damping because of the resistance, the $\mathrm{k}$ factor is introduced, which depends on the $\mathrm{R} / \mathrm{X}$ ratio of the sc impedance[4],[6] and it is acquired by the equation:

$$
k=1.02+0.98 e^{-3(R / X)}
$$

where a maximum DC component is assumed. Normally the sc current rating of the switchgear is based on $\mathrm{I}_{\mathrm{k}}$ " and given in $\mathrm{kA}$. The short circuit Power (SCP) is derived by the equation:

$$
S^{\prime \prime}=\sqrt{3} I_{3 k p}^{\prime \prime} U_{n}
$$

where $I_{3 k p}^{\prime \prime}$ stands for the initial three-phase sc current [6]. It has to be mentioned that the SCP has no physical meaning as peak currents and voltages do not act simultaneously. During the sc, the voltage in the fault position is very low or even zero. However this value can be used to determine the strength of the equipment, but most of the time the SCP is used to calculate the Thevenin impedance of the grid where the feeder is connected to. As in most cases the biggest stress occurs during 3 ph faults, only this case will be considered.

\section{A. Synchronous Generator (SG)}

Synchronous generators are mainly used in CHP plants as well as small hydro stations. Due to their separated excitation system they can supply a sustained sc current. The literature provides an analytical solution to estimate the sc contribution of the synchronous generator. According to [7],[8] when a 3 ph bolted fault occurs the value of the current is:

$$
\begin{aligned}
i(t)=\sqrt{\frac{2}{3}} U_{n}\left[\left(\frac{1}{X_{d}^{\prime \prime}}-\frac{1}{X_{d}^{\prime}}\right) \exp \left(-t / T_{d}^{\prime \prime}\right)+\left(\frac{1}{X_{d}^{\prime}}-\frac{1}{X_{d}}\right) \exp \left(-t / T_{d}^{\prime}\right)\right. \\
\left.+\frac{1}{X_{d}}\right] \sin (\omega t+\phi)-\sqrt{\frac{2}{3}} \frac{U_{n}}{X_{d}^{\prime \prime}} \sin (\phi) \exp \left(-t / T_{a}\right) \\
\text { where } X_{d}^{\prime \prime}: \text { subtransient reactance, } \\
X_{d}^{\prime}: \text { transient reactance, } \\
\mathrm{T}_{d}: \text { subtransient time constant, } \\
\mathrm{T}_{d}: \text { transient time constant, } \\
\mathrm{T}_{a}: \text { aperiodic time constant, } \\
\phi: \text { phase angle of the stator voltage when the sc }
\end{aligned}
$$

occurs.

The dc component which depends on the time the fault occurs is given by the last term. In IEC, the generator is modeled as a voltage source behind the equivalent impedance which includes the subtransient reactance of the machine and a resistance (Fig. 3) which is not equal to the stator resistance but it is much bigger. The value of this resistance depends on the rating of the generator. It is used to calculate the peak current and takes into account the decay of the AC and DC component during the first half cycle [4]. Because instead of the subtransient voltage an equivalent voltage source is used, the impedance is corrected with a $\mathrm{K}_{\mathrm{G}}$ factor which can be calculated according to [5].

In Fig. 4 the maximum sc current of a CHP plant (data provided in Appendix) is depicted.

\section{B. Asynchronous Generator $(A G)$}

These generators are mainly used in wind farms as well as in small hydro stations. There are two types of $\mathrm{AG}$, the squirrel cage induction generator (SCIG) and the wound rotor induction generator (WRIG). WRIG provides the capability to control the electrical characteristics of the machine. The main difference between $\mathrm{AG}$ and $\mathrm{SG}$ in sc behavior is that $A G$ receives the excitation from the network, therefore in case 


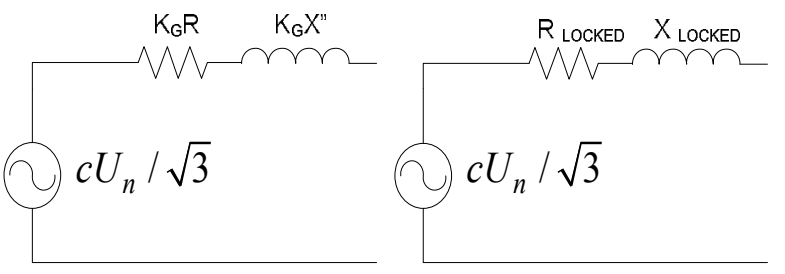

Fig. 3. IEC SG equivalent for SG and AG

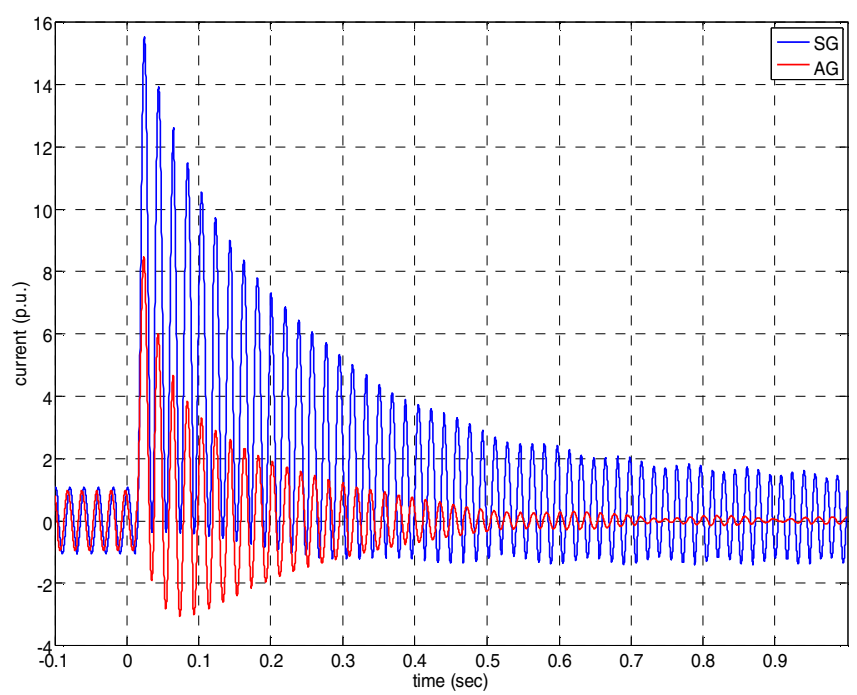

Fig. 4. Sc current during a 3 ph bolted fault in $\mathrm{AG} / \mathrm{SG}$

of a 3 ph fault this network excitation is lost completely. Due to constant flux theorem, AG is still able to feed a fault current for certain period of time. It contributes mainly to the peak current. However there is almost no contribution to the thermal sc current. Moreover the peak current of AG is lower than that of the SG for the same rating (Fig. 4). In sc studies, AG which are directly coupled (SCIG), are treated as big motor loads. Since the sc is supplied only during the subtransient period (after that the remaining magnetic field is lost), the dynamics of the mechanical part of generator (rotor acceleration) has nearly no influence on its short-circuit behavior. Therefore the machine itself is an appropriate representation. Models for sc analysis can be found on [8-10] where it can be derived from the equivalent circuit that the sc current is:

$i(t)=\frac{\sqrt{2} U_{n}}{X_{s}^{\prime \prime}}\left[\exp \left(-t / T_{s}^{\prime \prime}\right) \sin (\phi)-(1-\sigma) \sin \left(\omega_{S} t+\phi\right) \exp \left(-t / T_{r}^{\prime \prime}\right)\right]$

where $X_{\mathrm{S}}^{\prime \prime}$ : subtransient reactance,

$T_{\mathrm{s}}^{\prime \prime}$ : subtransient stator time constant,

$\phi$ : phase angle of stator voltage when the sc occurs,

$\sigma$ : total leakage coefficient,

$\omega_{s}:$ synchronous angular speed,

$T_{\mathrm{r}}^{\prime \prime}$ : subtransient rotor time constant.

In IEC standards the locked rotor impedance behind a voltage source is used to model the machine (Fig. 3). The locked rotor impedance is acquired through the locked rotor test. The $\mathrm{R} / \mathrm{X}$ ratio is depending on the size of the machine and a good approximation (if the value is not known) can be found on [4].

\section{Doubly Fed Induction Generator (DFIG)}

The DFIG generator has received a lot of interest due to its special characteristics that make it quite attractive for implementation of variable speed wind turbine concept [11]. Although it is partly decoupled by a converter, which is used to control active and reactive power through the rotor circuit of generator, the majority of the power is injected by the stator. Therefore it is correct to use the classical representation in sc studies [12]. However, special attention should be paid, in case if a crowbar protection system is incorporated as it shown in. Apart from enhancing the stability during disturbances, the purpose of the crowbar is to protect the rotor-side converter. Due to the magnetic coupling between the rotor and the stator during fault situations, high currents can flow through the rotor and damage the converter. In these cases, the crowbar is switched on, and the rotor-side converter is short-circuited. In that situation the DFIG behaves like a squirrel cage induction generator. In [13] an approach to include the crowbar effect on the sc current is made, as well as to calculate the value of the impedance, which, on one hand, is sufficient to eliminate the peak current, but, on the other hand, also not to induce voltages that can damage the converter.

In order to evaluate the affect of the crowbar protection in the sc contribution, a simulation with a DFIG wind turbine was performed in Digsilent Power Factory. A 5.9MVA DFIG is connected through a 3-winding transformer to the $30 \mathrm{kV}$ network. A sc occurs in the terminals of the transformer and lasts for 400ms. In Fig. 6 the effect of the crowbar can be easily seen. The use of thyristors for switching allows response time of less than $5 \mathrm{~ms}$. The fast reaction of the controller of the crowbar, which is set to bypass the converter when the current exceeds a certain value (in this case 2 p.u.), manages to reduce the peak current from 1206A to 760 A (Table I).

Problems can arise when IEC standards are used to calculate the peak sc current. The peak current is also calculated according to IEC with the following assumptions:

1)The generator is treated as an asynchronous motor; 2)The contribution of the converter is neglected; 3)The transformer is treated as a 2-winding (HV-MV). When there is no crowbar protection in the DFIG, the data of the asynchronous generator (locked rotor impedance) is used, and the peak value is calculated (Table I). The result is $12.3 \%$

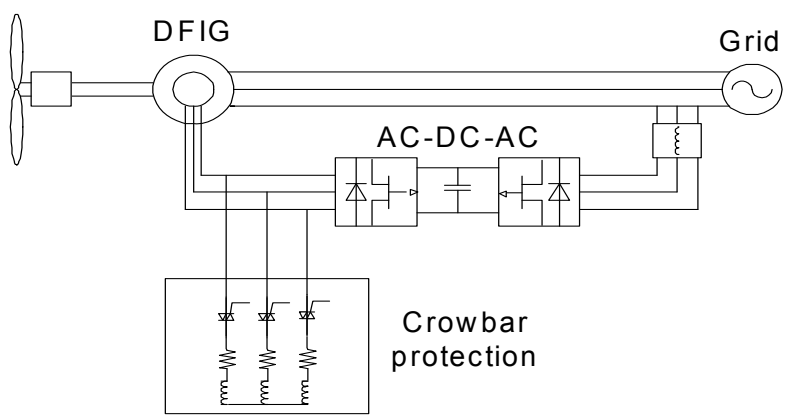

Fig. 5. Schematic diagram of DFIG with crowbar protection 


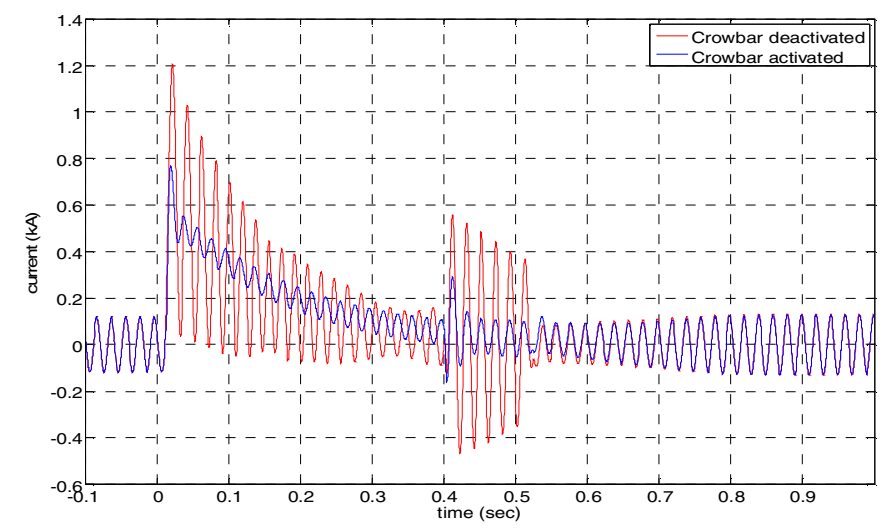

Fig. 6. SC current supplied by the DFIG (with/without crowbar)

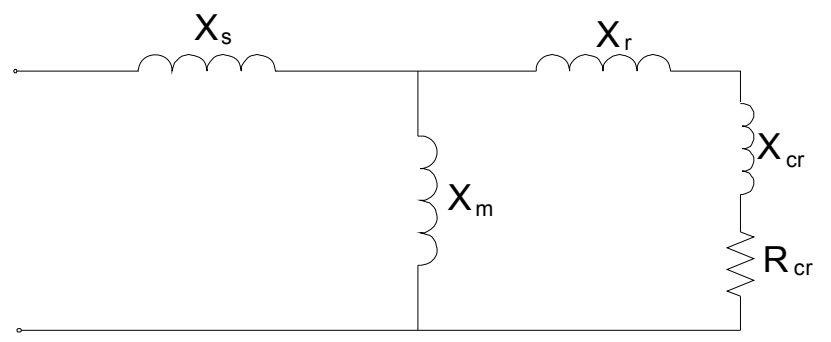

Fig. 7. Equivalent circuit of a DFIG with crowbar protection

TABLE I

PEAK SHORT CIRCUIT CURRENT SUPPLIED BY THE DFIG (A)

\begin{tabular}{|l|c|c|}
\hline & Crowbar protection on & Crowbar protection off \\
\hline Simulation results & 760 & 1206 \\
\hline IEC 60909 & 725 & 1354 \\
\hline Difference & $-5.2 \%$ & $+12.3 \%$ \\
\hline
\end{tabular}

higher than the exact value, acquired by the simulations. When the crowbar protection is activated, the parameters of the machine are changed. The additional impedance has to be taken into consideration. In order to understand how the crowbar affects the electric characteristics of the generator, the equivalent circuit of an induction generator is presented in Fig. 7. The resistances of the motor and stator are neglected due to their small values. However, the resistance of the crowbar is not negligible and depending on the overall $\mathrm{R} / \mathrm{X}$ ratio has to be taken into consideration. As it can be seen, the crowbar is connected in series with the rotor, therefore it acts as an external load on a wound rotor induction machine. This external load affects the characteristics of the machine (torque-slip curve, locked rotor impedance etc.) in a way that is explained in [14]. In order to acquire the new value of the locked rotor impedance, an induction motor with rotor impedance equal to the sum of the value given by the machine datasheet and the value of the crowbar impedance is considered. Then the new locked rotor impedance is calculated through the locked rotor current to nominal current ratio $\left(\mathrm{I}_{\mathrm{L}} / \mathrm{I}_{\mathrm{N}}\right)[4]$.

According to the IEC standards, if the $\mathrm{R} / \mathrm{X}$ ratio is below 0.35 , the resistance in the equivalent circuit can be omitted. In Table I the calculated value of the peak current is given without considering the resistances in the circuit. In case the resistances were taken into consideration, the calculations would have given a lower value. In fact the value was already lower than the exact value.

An explanation for this is the following. In order to acquire the impedance through the locked rotor test, a machine with an equivalent rotor impedance (which would incorporate both rotor and crowbar impedances) has to be considered. In reality, the additional impedance does not exist on the moment of the sc as the crowbar is connected a short time after the fault has occurred. Therefore it cannot have the same effect as by increasing the rotor impedance. Finally, IEC does not take into consideration the contribution from the inverter.

\section{Test Network}

In order to evaluate the influence of penetration of different DG types on the sc current and to estimate the accuracy of the IEC standard, a case study is simulated based on a real distribution network in the Netherlands. The test grid used for the simulation is a $10 \mathrm{kV}$ cable network consisting of several radial feeders. The DFIG and AG are connected to the feeders through step up transformers, while the CHPs (SG) are directly connected at the $10 \mathrm{kV}$ level, as a common practice in the Netherlands. In the feeders aggregated loads with a total consumption of 26.8MVA are also connected. The penetration level of DG [15] in the base case study is $28.9 \%$. The MV voltage grid is interconnected with the HV network through two parallel transformers. In normal operation, only one of the two transformers is on duty, and therefore the sc contribution from the HV grid is reduced to half. The main busbar is rated for a peak current of $125 \mathrm{kA}$.

A sc is performed at the $10 \mathrm{kV}$ substation busbar. The fault contribution from the distribution network, where the DG units are connected, and the contribution from the HV network are calculated using both IEC standard and simulations. In Fig. 8 the equivalent circuit for the IEC calculations with the values referred to the $10 \mathrm{kV}$ level can be found. In Table II there is a summary of the results. It can be seen that the IEC standard gives results with certain safety margin in almost all cases. Only when a DFIG unit with a crowbar protection is installed, the estimated value using the standard does not have any safety margin and is very close to the simulation result. The error between the actual values is in any case below $15 \%$. With this penetration level the contribution of the DG to the sc level is up to $10.98 \%$, which is rather low in comparison with the contribution from the HV grid.

It is interesting to see what happens when the DG share substation busbar until either the limitation for the peak sc

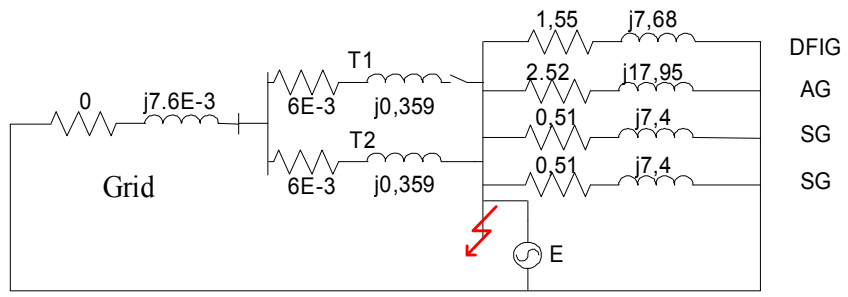

Fig. 8. IEC equivalent circuit for sc analysis 
TABLE I

PEAK SHORT CIRCUIT CURRENT (kA)

\begin{tabular}{|c|c|c|c|c|c|}
\hline & DFIG & AG & SG1 & SG2 & Grid \\
\hline IEC standard & 2.182 & 0.89 & 2.44 & 2.44 & 52.62 \\
\hline Simulation & 2.294 & 0.78 & 2.126 & 2.126 & 47.7 \\
\hline Error & $-4.8 \%$ & $14.10 \%$ & $14.77 \%$ & $14.77 \%$ & $8.3 \%$ \\
\hline
\end{tabular}

increases. 3 scenarios will be considered for the rise of DG production. In each scenario the network is expanded by generators of one specific type connected to the MV current of the busbar is reached or the HV/MV transformer becomes overloaded. Voltages problems with this structure do not occur (since the generators are connected directly to the substation) and stability issues are not examined.

In the first scenario an expansion with only DFIG generators is considered. In this case the HV/MV transformer becomes overloaded before the sc level of the substation busbar exceeds the limitation, because sc contribution of DFIG is low. Therefore, even though IEC calculations introduce certain safety margin to the sc current value, they cannot impose limitations. The same applies for the second scenario with the expansion using AG. However, when only CHPs are installed, the use of IEC standard or EMT simulation makes the difference. According to IEC calculations the limitation for the peak sc current on the busbar is reached faster than in case EMT simulation is used. Employing EMT simulations for sc current calculation would result in the possibility of installing extra generators with a rated power of 10 MVA (equivalent for 5 extra CHP plants) without violation of the sc current limit of the busbar or loading limits of the HV/MV transformer.

\section{CONCLUSIONS}

As it was seen by the simulations, each DG unit contributes in a different way to the sc current. Both synchronous and asynchronous generators have a high peak current, which in the first case can reach up to 15 p.u. The DFIG is a specific case of AG, when the crowbar protection is installed. In this case the peak value of the sc current is reduced considerably, due to the fast reaction of the controller. As it was shown, IEC standards do not provide yet a way to treat this type of DG. An approach to consider it as a wound motor gave a good approximation; however, the peak current obtained using IEC standard is below the actual value determined by means of simulation. Standards have to consider the new type of DG and give formulas in order to calculate the sc currents with adequate accuracy.

After that, an investigation on a distribution network consisting of radial feeders was made in order to evaluate how the increase of penetration level of various DG can affect the sc level of the substation busbar. Results were obtained using both IEC standard and EMT simulation. It was shown that due to the different sc behavior of DG, the number of the DG which can be connected to the substation busbar depends on the type of the DG. In this test network it was found that for the CHP expansion scenario, the IEC calculations were preventing a higher penetration because of their safety margin. Therefore EMT simulations have to be carried out to allow maximum penetration level.

\section{APPENDIX}

The parameters of the test network can be found below:

External Grid:

$\begin{array}{ll}\mathrm{V}=150 \mathrm{kV} & \mathrm{S} "=17231 \mathrm{MVA} \\ \mathrm{c}=1.1 & \mathrm{X} / \mathrm{R}=10\end{array}$

DFIG:

$\begin{array}{llll}\mathrm{V}=3.3 \mathrm{kV} & \mathrm{S}=5.89 \mathrm{MVA} & \cos \varphi=0.85 & \mathrm{p}=2 \\ \mathrm{R}_{\mathrm{S}}=0.02 \mathrm{p} . \mathrm{u} & \mathrm{X}_{\mathrm{S}}=0.13 \mathrm{p} . \mathrm{u} . & \mathrm{X}_{\mathrm{m}}=2.5 \mathrm{p} . \mathrm{u} . & \mathrm{I}_{\mathrm{K}} / \mathrm{I}_{\mathrm{L}}=5.7 \\ \mathrm{R}_{\mathrm{cr}}=\mathrm{X}_{\mathrm{cr}}=0.1 \mathrm{p} . \mathrm{u} & & & \end{array}$

Asynchronous Generator:

$\begin{array}{llll}\mathrm{V}=3.3 \mathrm{kV} & \mathrm{S}=1.5 \mathrm{MVA} & \cos \varphi=0.86 & \mathrm{p}=2 \\ \mathrm{R}_{\mathrm{S}}=0.02 \mathrm{p} . \mathrm{u} & \mathrm{X}_{\mathrm{S}}=0.13 \mathrm{p} . \mathrm{u} . & \mathrm{X}_{\mathrm{m}}=2.6 \mathrm{p} . \mathrm{u} . & \mathrm{I}_{\mathrm{K}} / \mathrm{I}_{\mathrm{L}} 5.7\end{array}$

Synchronous Generator (CHP):

$$
\begin{aligned}
& \mathrm{V}=3.3 \mathrm{kV} \quad \mathrm{S}=1.75 \mathrm{MVA} \quad \text { p.f.=1cap } \quad \mathrm{X}_{\mathrm{d}}{ }^{\prime \prime}=0.1 \text { p.u. } \\
& \mathrm{X}_{\mathrm{d}}=2.3 \mathrm{p} . \mathrm{u} .
\end{aligned}
$$

Substation Transformers $\left(\mathrm{DY}_{\mathrm{n} 5}\right)$ :

$$
\begin{array}{ll}
\mathrm{V}=150 / 11 \mathrm{MVA} & \mathrm{S}=66 \mathrm{MVA} \\
\mathrm{u}_{\mathrm{k}}=20 \% & \mathrm{P}_{\mathrm{cu}}=224 \mathrm{~kW}
\end{array}
$$

DFIG Transformer $\left(D Y_{n 5} Y_{n 5}\right)$ :

$$
\begin{array}{ll}
\mathrm{V}=11 / 3.3 / 0.69 \mathrm{MVA} & \mathrm{S}=5.6 \mathrm{MVA} \\
\mathrm{P}_{\mathrm{cu}}=13.15 \mathrm{~kW} & \mathrm{u}_{\mathrm{k}}(\mathrm{HV}-\mathrm{HV})=5.35 \%
\end{array}
$$

AG Transformer $\left(\mathrm{DY}_{\mathrm{n})}\right.$

$$
\begin{array}{ll}
\mathrm{V}=11 / 3.3 & \mathrm{~S}=1.9 \mathrm{MVA} \\
\mathrm{P}_{\mathrm{cu}}=12.8 \mathrm{~kW} & \mathrm{u}_{\mathrm{k}}(\mathrm{HV}-\mathrm{MV})=5.35 \%
\end{array}
$$

\section{ACKNOWLEDGMENT}

This research has been performed within the framework of the research program 'Intelligent Power Systems' that is supported financially by Senter Novem. Senter Novem is an agency of the Dutch Ministry of Economic Affairs.

\section{REFERENCES}

[1] S. R. Wall, "Performance of inverter interfaced distributed generation,", 2 ed 2001, pp. 945-950.

[2] M. E. Baran and M. El, I, "Fault analysis on distribution feeders with distributed generators," IEEE Transactions on Power Systems, vol. 20, no. 4, pp. 1757-1764, 2005.

[3] T. Ackermann and V. Knyazkin, "Interaction between distributed generation and the distribution network: operation aspects," in IEEE/PES Transmission and Distribution Conference and Exhibition Piscataway, NJ, USA: IEEE, 2002, pp. 1357-1362.

[4] "IEC 60909-0 Calculation of currents," IEC,July2001.

[5] "IEC TR 60909-1 Factors for the calculation of short -circuit currents according to IEC 60909-0," IEC,2001. 
[6] D. Tsanakas, Special Chapters on Electrical Power Systems University of Patras Publishers, 2003.

[7] J. Grainger and W. Stevenson, Power System Analysis McGraw-Hill, 1994.

[8] P. Anderson, Analysis of Faulted Power Systems IEEE, 1995.

[9] P. Kovacs, Transient Phenomena In Electrical Machines Elsevier, 1984.

[10] T. Sulawa, Z. Zabar, D. Czarkowski, Y. TenAmi, L. Birenbaum, and S. Lee, "Evaluation of a 3- phi bolted short-circuit on distribution networks having induction generators at customer sites," IEEE Transactions on Power Delivery, vol. 22, no. 3, pp. 1965-1971.

[11] S. Muller, M. Deicke, and R. W. De Doncker, "Doubly fed induction generator systems for wind turbines," Industry Applications Magazine, IEEE, vol. 8, no. 3, pp. 26-33, 2002.
[12] M. S. Vicatos and J. A. Tegopoulos, "Transient state analysis of a doubly-fed induction generator under three phase short circuit," Energy Conversion, IEEE Transaction on, vol. 6, no. 1, pp. 62-68, Jan.1999.

[13] J. Morren and S. W. H. de-Haan, "Short-circuit current of wind turbines with doubly fed induction generator," IEEE Transactions on Energy Conversion, vol. 22, no. 1, pp. 174-180.

[14] Wildi T., Electrical Machines, Drives and Power Systems, 4th ed Prentice Hall, 2000.

[15] M. K. Donnelly, J. E. Dagle, D. J. Trudnowski, and G. J. Rogers, "Impacts of the distributed utility on transmission system stability," Power Systems, IEEE Transactions on, vol. 11, no. 2, pp. 741-746, May1996. 